\title{
The Effect of Multivitamins, Minerals, and Q10 on Precancerous Lesions of the Cervix
}

\author{
Mitra Modarres Gilani ${ }^{\circledR}$, Azam Sadat Mosavi', Setare Akhavan', Mehrangiz Zamani2 ${ }^{*}{ }^{\circledR}$, Mohammad Ali \\ Mohsenpour $^{3,4}{ }^{\circledR}$, Fatemeh Mohsenpour ${ }^{2}$, Azar Pir Dehghan², Danial Farhadi², Fazezeh Torkzaban²
}

\begin{abstract}
Objectives: Invasive cervical cancer is one of the most fatal genital cancers of women which can be detected by having Pap smear in precancerous stage. Various approaches can be taken for treating or preventing the progress of these precancerous lesions. The aim of this study was to investigate the cytopathological and colposcopic response of precancerous lesions to multivitamin, mineral (multimineral), and coenzyme Q10 supplements.

Materials and Methods: The present randomized clinical trial was conducted on 120 participants with clinical complaints or abnormal Pap smear test results. The intervention and control groups received supplemental and placebo treatments, respectively, for 3 months after a primarily Pap smear test. The Pap smear test was also performed after the treatment and patients with abnormal results were screened by colposcopy. Data were analyzed by SPSS software and P-value less than 0.05 was considered significant.

Results: The percentage of participants in the intervention and control groups were $40 \%$ and $28.3 \%$ in the age range of $20-29,26.7 \%$ and $41.7 \%$ in the age range of $30-39$, and finally $33.3 \%$ and $30 \%$ over 40 years of age, respectively $(P=0.19)$. The percentage of normalization in Pap smear test result was $83.3 \%$ and $53.3 \%$ in the intervention and control groups, respectively $(P<0.001)$.

Conclusions: It was found that short-term usage of multi-mineral and Q10 supplements may decrease the risk of cervical cancer in women with abnormal Pap smear. However, studies with larger population and longer trial period are needed for further investigation. Keywords: Precancerous, Dietary supplement, Q10, Cervix, Colposcopy
\end{abstract}

\section{Introduction}

Invasive cervical cancer is considered as one of the most fatal cancers of female reproductive system. Additionally, it is known as the second malignant cancer after breast cancer and the third prevalent cancer of female genital tract (1-3). Moreover, uterine cancer is the fourth most prevalent cancer among all cancers (with the outbreak of $6.64 \%$ ) and accounts for $34.2 \%$ of cancers among females screened in Iran (4). In the meantime, cervical dysplasia may progress to cervical cancer as a precancerous lesion (5).

Cervical cancer has a prolonged pre-cancerous stage, the progression period of which may take 15 to 20 years from precancerous to invasive malignancy (6). Therefore, diagnosing pre-cancerous lesions and choosing an appropriate therapeutic modality is of enormous importance.

Prevalence and mortality from cervical cancer have been reduced due largely to the development of screening procedures as Pap smears in developed countries $(7,8)$.

Additionally, human papillomavirus (HPV) has been named as one of the most important risk factors for cervical cancer in low- and middle-income countries (9).

Furthermore, it has been reported that several factors including young age at the first sexual intercourse, having multiple sexual partners and not using condoms, taking oral contraceptives or supplements, simultaneous infection with HPV and HIV, being infected with other sexually transmitted diseases (STDs), and history of 5 or more full-term pregnancies may affect HPV infection rate (10). Cigarette smoking is another risk factor for cervical cancer, which can double its incidence rate based on the intensity and duration of smoking (11).

Some nutritional epidemiologic studies have revealed the positive effect of consuming higher amounts of fruits and vegetables in the prevention of uterine and cervical cancer $(12,13)$. On the other hand, low levels of plasma antioxidants have been associated with the increased incidence of precancerous lesion and cancer $(14,15)$.

It has been reported that serum folate and vitamin B12 levels significantly decrease in patients with invasive cervical cancer (16). Moreover, folate intake is associated with the improvement of cervical cytology (17).

On account of the abovementioned, as well as 
considering the lack of related studies in Iran, the aim of this study was to investigate the effect of multi-mineral and Q10 supplements on the cytopathological and colposcopic response of precancerous lesion of the cervical cancer among women.

\section{Materials and Methods \\ Participants}

The study group comprised 130 patients who had referred to the Gynecologic Ward of Fatemieh hospital, Hamadan, Iran, with abnormal Pap smear test results. The patients were consulted and asked to sign informed consent forms if they wished to take part in the study.

Liquid-based cytology was used for cervical screening, and patients with abnormal Pap test results received colposcopy and biopsy. Atypical squamous cells of undetermined significance (ASC-US), atypical squamous cells (ASC-H), and low-grade squamous intraepithelial lesion (LSIL), as well as clinical symptoms such as bleeding after intercourse, changes in the color of discharge from the vagina, and cervical wound were considered as examples of common abnormal Pap test results.

Colposcopy was done on all patients after consultation with them. The macroscopic characteristics of the cervix was examined prior to being exposed to $3 \mathrm{~mL}$ of $3 \%$ acetic acid for 30 seconds or $3 \mathrm{~mL}$ of $10 \%$ Lugol's solution for 30 seconds. Then cervix was carefully examined by colposcopy. Afterward, the macroscopic and colposcopic characteristics of the cervix, as well as the $T$ zone characteristics, stained with acetic acid and Lugol's solution, and abnormal vessels (18-20) were checked and recorded in the patient's checklist.

If the pathological results showed mild dysplasia, presence of atypical koilocytes in histology, and lack of indication for interventions, participants would be included in the study and randomized in the intervention or control groups using random blocks.

\section{Intervention}

Intervention group received multi-mineral and Q10 supplements at a dose of $30 \mathrm{mg}$ daily for a period of three months and the control group received 2 tablets with the same physical characteristics as the placebo. Using the supplements was checked by continuous patients checking (CPC) method in a monthly period by phone calls.

\section{Pap Smear Test}

At the end of the study, a Pap smear test would be performed again if the result was positive, and had the indication for colposcopy. If any lesions were observed, biopsy would be performed and the result would be examined by a pathologist who did not know the patients.

Recovery was defined as the absence of any lesions in cervical intraepithelial neoplasia (CIN1) and atypical koilocytic cell in the cytopathology result. Candidates with CIN1 lesions or above (CIN2 and CIN3) were classified as non-respondents to the treatment. Individuals who did not report any injuries were considered as recovered individuals.

\section{Statistical Analysis}

All patients' data were recorded in a checklist from the beginning of the study. The data were analyzed using chi-square test. The $P$ value less than 0.05 was considered significant. It should be noted that the data were analyzed by SPSS software version 16.0 in this study.

\section{Results}

Out of 130 participants, 4 did not meet inclusion criteria, and the remaining were randomly assigned to the intervention and control groups ( $n=63$ per group). Three participants were omitted from both groups at the end of third month of treatment. The total number of women in each group for final analysis was 60 (Figure 1).

Both groups were matched regarding their age. There were no significant differences between the groups in terms of demographic variables including education, marriage age, number of live births (parity), area of residency, history of smoking, having multiple sex partners, diabetes mellitus, and history of cancer in firstdegree relatives (Table 1 ).

The results of Pap smear test for the intervention group were as normal (83.3\%), ASCUS (15\%), ASC-H (0\%), LSIL (1.7\%), and HSIL (0\%), and for the control group were as normal (53.3\%), ASCUS (33.3\%), ASC-H (5\%), LSIL (5\%) and HSIL (3.3\%). The normal frequency of Pap smear in the intervention group was significantly higher than that in the control group $(P<0.001$, Table 2$)$.

Out of the participants, 6 in the intervention group and 25 in the control group did not report normal Pap smear results in the third month. The frequency of abnormal result for the intervention group was significantly lower than that for the control group $(P<0.001)$ in all abnormal categories.

It should be noted that the most important complaints in the intervention group were about bleeding, spotting (38.3\%), lesions of the cervix (21.7\%), warts (3.3\%), discharge (8.3\%), ASUCUS (20\%), and ASCH (8.3\%), and in the control group were of bleeding, spotting $(21.7 \%)$, cervical lesions (33.3\%), warts (5.0\%), discharge (18.3\%), and ASUCUS (21.7\%).

\section{Discussion}

The higher dietary consumption, as well as circulating levels of certain micronutrients can be protective against cervical cancer. Moreover, the lack of antioxidants may lead to pre-cancerous cervical lesions; hence multimineral and Q10 supplements can have a preventive role against CIN (21).

The results of the present study showed that the consumption of health supplements including multimineral and Q10 for 3 months led to 30\% improvement in 


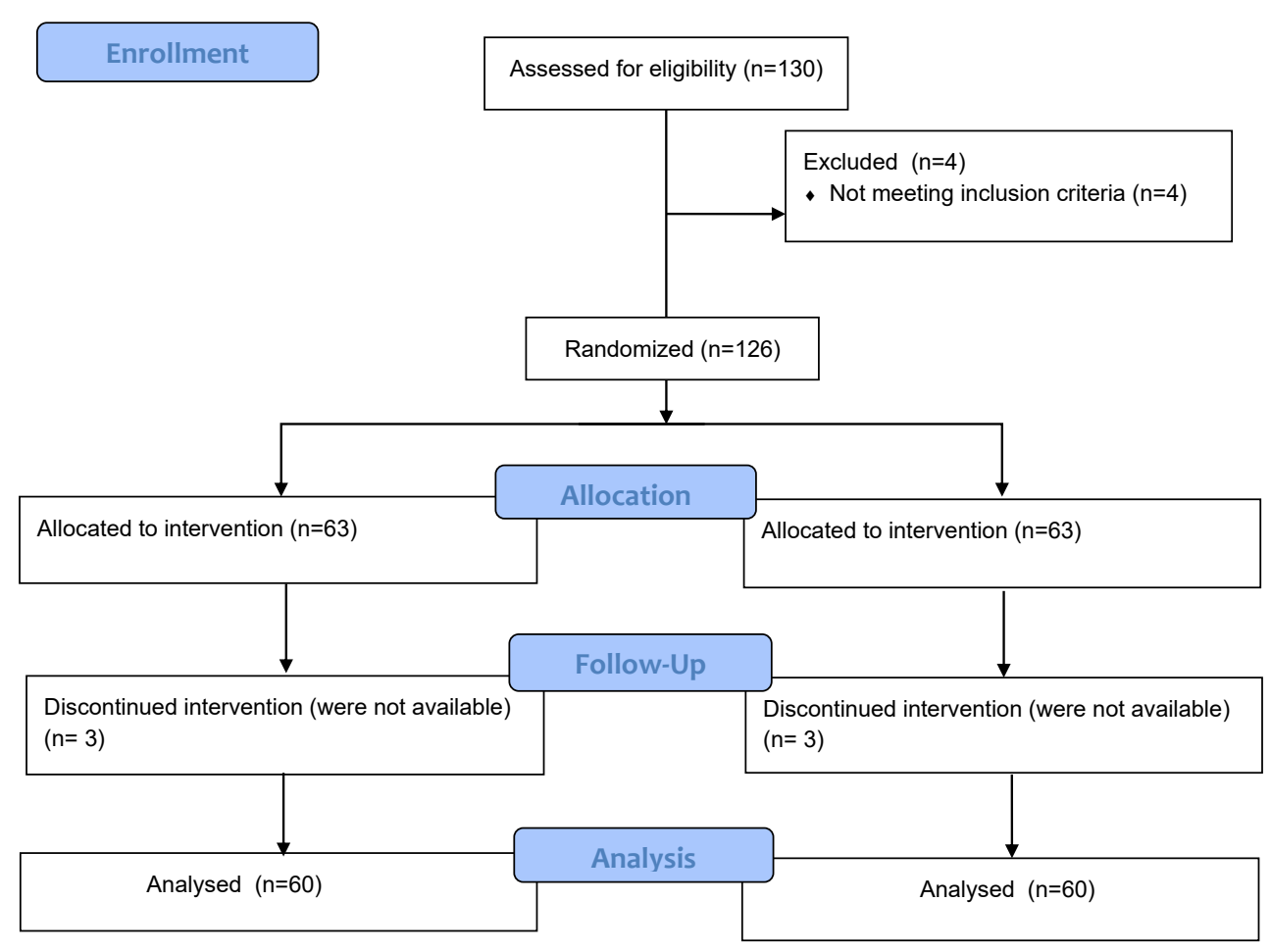

Figure 1. Flow Diagram of the Study.

Table 1. Demographic Characteristics of Participants

\begin{tabular}{|c|c|c|c|c|}
\hline Variables & & $\begin{array}{c}\text { Intervention } \\
\text { No. }(\%)\end{array}$ & $\begin{array}{l}\text { Control } \\
\text { No. }(\%)\end{array}$ & $P$ Value \\
\hline \multirow{3}{*}{ Age (y) } & $20-30$ & $24(40.0)$ & $17(28.3)$ & \multirow{3}{*}{0.194} \\
\hline & $30-40$ & $16(26.7)$ & $25(41.7)$ & \\
\hline & $>40$ & $20(33.3)$ & $18(30.0)$ & \\
\hline \multirow{3}{*}{ Education } & $\begin{array}{l}\text { Elementry or } \\
\text { illitrate }\end{array}$ & $18(30.0)$ & $28(46.7)$ & \multirow{3}{*}{0.135} \\
\hline & $\begin{array}{l}\text { Lower than } \\
\text { diploma }\end{array}$ & $15(25.0)$ & $14(23.3)$ & \\
\hline & Diploma or higher & $27(45.0)$ & $18(30.0)$ & \\
\hline \multirow{3}{*}{$\begin{array}{l}\text { Marriage } \\
\text { age }(y)\end{array}$} & $<20$ & $22(36.7)$ & $28(46.7)$ & \multirow{3}{*}{0.337} \\
\hline & $20-30$ & $30(50.0)$ & $22(36.7)$ & \\
\hline & $>30$ & $8(13.3)$ & $10(16.7)$ & \\
\hline \multirow{3}{*}{ Parity } & None & $8(13.3)$ & $4(6.7)$ & \multirow{3}{*}{0.289} \\
\hline & $1-2$ & $21(35.0)$ & $28(46.7)$ & \\
\hline & $\geq 3$ & $31(51.7)$ & $28(46.7)$ & \\
\hline \multirow{2}{*}{$\begin{array}{l}\text { Area of } \\
\text { residency }\end{array}$} & City & $39(65.0)$ & $44(73.3)$ & \multirow{2}{*}{0.323} \\
\hline & Village & $21(35.0)$ & $16(26.7)$ & \\
\hline \multirow{2}{*}{ Smoking } & Yes & $9(15.0)$ & $6(10.0)$ & \multirow{2}{*}{0.408} \\
\hline & No & $51(85.0)$ & $54(90.0)$ & \\
\hline \multirow{2}{*}{$\begin{array}{l}\text { Multi } \\
\text { partner }\end{array}$} & Yes & $2(3.3)$ & $1(1.7)$ & \multirow{2}{*}{0.500} \\
\hline & No & $58(96.7)$ & $59(98.3)$ & \\
\hline \multirow{2}{*}{ Diabetes } & Yes & $4(6.7)$ & $6(10.0)$ & \multirow{2}{*}{0.372} \\
\hline & No & $56(93.3)$ & $54(90.0)$ & \\
\hline \multirow{4}{*}{$\begin{array}{l}\text { History of } \\
\text { cancer }\end{array}$} & No & $51(85.0)$ & $49(81.7)$ & \multirow{4}{*}{ - } \\
\hline & Cervix & $3(5.0)$ & $5(8.3)$ & \\
\hline & Breast & $3(5.0)$ & $4(6.7)$ & \\
\hline & Ovary & $3(5.0)$ & $2(3.3)$ & \\
\hline
\end{tabular}

Pap smear test results compared to the placebo treatment. These results were consistent with the findings of Piyathilake et al (22) who reported that high levels of plasma folic acid were associated with a significantly lower risk of progressing CIN lesions. There is a consensus in the use of antioxidants in preventing malignancies, while the type and dosage of consumed supplement is an ongoing controversy among experts (23). Another study demonstrated that consumption of B6 supplements can reduce the risk of breast cancer; this result agrees with the results of our study. It should be noted that the cervical cancer was not investigated in our study (24).

A study by Palan et al (25) revealed that women with cervical neoplasia have meaningfully lower plasma levels of Q10 compared to healthy women. Although the plasma level of Q10 was not measured in our study, the results were consistent based on the clinical assessment. It should be noticed that in our study, the confounding variables were the same for both intervention and control groups and did not affect the results.

According to the findings, $78.8 \%$ of participants with normal Pap smear test results were not smoker, while $12.2 \%$ of smokers had normal Pap smear results. This difference was not significant, which might have been affected by our sample size. This result might have been significant if we had had a bigger sample size. Previous studies indicate that smoking could be a risk factor for cervical cancer, though such result was not confirmed in our study (26). 
Table 2. Frequency of Abnormal Pathology for Both Groups Before and After the Study

\begin{tabular}{llccc}
\hline & & $\begin{array}{c}\text { Intervention } \\
\text { No. }(\%)\end{array}$ & $\begin{array}{c}\text { Control } \\
\text { No. }(\%)\end{array}$ & P Value* \\
\hline \multirow{4}{*}{ Before } & CIN & $17(28.3)$ & $19(31.7)$ & \\
& $\begin{array}{l}\text { Atypical cell with } \\
\text { koilocytosis }\end{array}$ & $43(71.7)$ & $41(68.3)$ & 0.69 \\
& Total & $60(100)$ & $60(100)$ & \\
& Normal & $54(90)$ & $35(58.3)$ & \\
After & CIN $=1$ & $2(3.33)$ & $14(23.3)$ & \\
& CIN $\geq 2$ & - & $5(8.03)$ & $<0.001$ \\
& Atypical cell with & $4(6.66)$ & $6(10)$ & \\
koilocytosis & $60(100)$ & $60(100)$ & \\
\hline
\end{tabular}

\section{Conclusions}

Form this study, it was found out that short-term usage of multi-mineral and Q10 supplements may decrease the risk of cervical cancer in women with abnormal Pap smear. However, studies with larger population and longer trial period are recommended for further investigation.

\section{Conflict of Interest}

Authors declare that they have no conflict of interests.

\section{Ethical Issues}

This clinical trial was registered in the Iranian Registry of Clinical Trials (identifier: IRCT2014102719694N1, https://www.irct.ir/trial/17549).

\section{Financial Support}

This research was financially supported by the Vice-Chancellor for Research of Hamadan University of Medical Sciences, Hamedan, Iran.

\section{References}

1. Almassi Nokiani F, Akbari H. Prevalence of invasive and pre- invasive cervical lesions in Kermanshah (2003-2007). The Journal of Qazvin University of Medical Sciences. 2009;13(1):42-48. [Persian].

2. Jafari Shobeiri M, Halimi, Dastranj, Shahamphar. Screening for cervical cancer and precancerous lesions in Tabriz. Med J Islam Repub Iran. 2007;21(1):1-10. [Persian].

3. Limpvanuspong B, Tangjitgamol S, Manusirivithaya S, Khunnarong J, Thavaramara T, Leelahakorn S. Prevalence of high grade squamous intraepithelial lesions (HSIL) and invasive cervical cancer in patients with atypical squamous cells of undetermined significance (ASCUS) from cervical pap smears. Southeast Asian J Trop Med Public Health. 2008;39(4):737-744.

4. Hemati K, Mohagheghi SMA, Mousavi Jarahi SAR, Khabaz Khoub M. Cancer Incidence in Ilam. Journal of Ilam University of Medical Sciences. 2009;17(3):24-32. [Persian].

5. Jemal A, Siegel R, Ward E, et al. Cancer statistics, 2008. CA Cancer J Clin. 2008;58(2):71-96. doi:10.3322/ca.2007.0010

6. Kola S, Walsh JC, Hughes BM, Howard S. Matching intra-procedural information with coping style reduces psychophysiological arousal in women undergoing colposcopy. J Behav Med. 2013;36(4):401412. doi:10.1007/s10865-012-9435-z

7. Safaei A, Khanlari M, Momtahen M, et al. Prevalence of high-risk human papillomavirus types 16 and 18 in healthy women with cytologically negative pap smear in Iran. Indian J Pathol Microbiol. 2010;53(4):681-685. doi:10.4103/0377-4929.72030
8. Amarin ZO, Badria LF, Obeidat BR. Attitudes and beliefs about cervical smear testing in ever-married Jordanian women. East Mediterr Health J. 2008;14(2):389-397.

9. Danaei G, Vander Hoorn S, Lopez AD, Murray CJ, Ezzati M. Causes of cancer in the world: comparative risk assessment of nine behavioural and environmental risk factors. Lancet. 2005;366(9499):1784-1793. doi:10.1016/s0140-6736(05)67725-2

10. Chelimo C, Wouldes TA, Cameron LD, Elwood JM. Risk factors for and prevention of human papillomaviruses (HPV), genital warts and cervical cancer. J Infect. 2013;66(3):207-217. doi:10.1016/j. jinf.2012.10.024

11. Roura E, Castellsague X, Pawlita M, et al. Smoking as a major risk factor for cervical cancer and pre-cancer: results from the EPIC cohort. Int J Cancer. 2014;135(2):453-466. doi:10.1002/ijc.28666

12. Cox BA, Crow WT, Johnson L. Current nutritional considerations for prevention of cervical cancer. Osteopathic Family Physician. 2012;4(3):81-84. doi:10.1016/j.osfp.2011.09.003

13. Zhang X, Dai B, Zhang B, Wang Z. Vitamin A and risk of cervical cancer: a meta-analysis. Gynecol Oncol. 2012;124(2):366-373. doi:10.1016/j.ygyno.2011.10.012

14. Palan PR, Mikhail MS, Basu J, Romney SL. Plasma levels of antioxidant beta-carotene and alpha-tocopherol in uterine cervix dysplasias and cancer. Nutr Cancer. 1991;15(1):13-20. doi:10.1080/01635589109514106

15. Yeo AS, Schiff MA, Montoya G, Masuk M, van Asselt-King L, Becker TM. Serum micronutrients and cervical dysplasia in Southwestern American Indian women. Nutr Cancer. 2000;38(2):141-150. doi:10.1207/s15327914nc382_1

16. Ferdous J, Khatun S, Biswas SK, Akter L, Keya KA. Serum concentration of folate, vitamin B 12 and homocysteine in patients of cervical cancer. Bangabandhu Sheikh Mujib Med Univ J. 2016;9(4):188-92. doi:10.3329/bsmmuj.v9i4.30104

17. Butterworth CE Jr. Effect of folate on cervical cancer. Synergism among risk factors. Ann N Y Acad Sci. 1992;669:293-299. doi:10.1111/j.1749-6632.1992.tb17108.x

18. Belinson JL, Pretorius RG, Zhang WH, Wu LY, Qiao YL, Elson P. Cervical cancer screening by simple visual inspection after acetic acid. Obstet Gynecol. 2001;98(3):441-444.

19. Benedet JL, Anderson GH, Boyes DA. Colposcopic accuracy in the diagnosis of microinvasive and occult invasive carcinoma of the cervix. Obstet Gynecol. 1985;65(4):557-562.

20. Hegde D, Shetty H, Shetty PK, Rai S. Diagnostic value of acetic acid comparing with conventional Pap smear in the detection of colposcopic biopsy-proved CIN. J Cancer Res Ther. 2011;7(4):454458. doi:10.4103/0973-1482.92019

21. Palan PR, Mikhail MS, Shaban DW, Romney SL. Plasma concentrations of coenzyme Q10 and tocopherols in cervical intraepithelial neoplasia and cervical cancer. Eur J Cancer Prev. 2003;12(4):321-326. doi:10.1097/01.cej.0000082608.47188.62

22. Piyathilake CJ, Macaluso M, Alvarez RD, Bell WC, Heimburger DC, Partridge EE. Lower risk of cervical intraepithelial neoplasia in women with high plasma folate and sufficient vitamin B12 in the post-folic acid fortification era. Cancer Prev Res (Phila). 2009;2(7):658-664. doi:10.1158/1940-6207.capr-08-0175

23. Arellano Ortiz AL, Jimenez Vega F, Salcedo Vargas M. [Dietary supplements as a treatment for cervical cancer: a systematic review]. Nutr Hosp. 2013;28(6):1770-1780. doi:10.3305/nutr hosp. v28in06.6816

24. Chou YC, $\mathrm{Chu} \mathrm{CH}$, Wu $\mathrm{MH}$, et al. Dietary intake of vitamin B6 and risk of breast cancer in Taiwanese women. J Epidemiol. 2011;21(5):329-336. doi:10.2188/jea.JE20100188

25. Kjellberg L, Hallmans G, Ahren AM, et al. Smoking, diet, pregnancy and oral contraceptive use as risk factors for cervical intra-epithelial neoplasia in relation to human papillomavirus infection. Br J Cancer. 2000;82(7):1332-1338. doi:10.1054/bjoc.1999.1100

(C) 2021 The Author(s); This is an open-access article distributed under the terms of the Creative Commons Attribution License (http:// creativecommons.org/licenses/by/4.0), which permits unrestricted use, distribution, and reproduction in any medium, provided the original work is properly cited. 